\title{
Bilateral optic neuropathy related to severe anemia in a patient with alcoholic cirrhosis: A case report and review of the literature
}

\author{
Lisa Humbertjean-Selton', Jérôme Selton², Nolwenn Riou-Comte', Jean-Christophe Lacour ${ }^{1}$, Gioia Mione', and \\ Sébastien Richard ${ }^{1,3}$ \\ 'Department of Neurology, Stroke Unit, University Hospital of Nancy; ${ }^{2}$ Department of Ophthalmology, Clinic St André, Vandoeuvre- \\ lès-Nancy; ${ }^{3}$ Centre d'Investigation Clinique Plurithématique CIC-P 1433, Inserm U1116, University Hospital of Nancy, Vandoeuvre- \\ lès-Nancy, France
}

Anemia appears frequently in patients with alcoholic liver disease (ALD) but has never been linked to bilateral nonarteritic anterior ischemic optic neuropathy (NAION). A 65-year-old woman with a medical history of alcoholic cirrhosis was admitted for bilateral NAION. On admission, she was found to have a low arterial pressure and severe normocytic anemia ( $48 \mathrm{~g} / \mathrm{L})$. The anemia was related to chronic bleeding due to antral gastritis along with other factors associated with ALD. The applied treatment consisted of urgent transfusion followed by high doses of proton-pump inhibitors, iron and vitamin supplementation, and support in lifestyle measures. Her hemoglobin levels remained stable after 2 years but the patient still suffered from visual loss. This case highlights the link between anemia and bilateral NAION in ALD patients. The optic nerve head is prone to infarction in this context due to the vascularization characteristics of ALD. Hemoglobin levels should be monitored in ALD patients to avoid the severe complication of NAION. (Clin Mol Hepatol 2018;24:417-423)

Keywords: Alcoholic liver disease; Alcoholic cirrhosis; Chronic alcohol consumption; Anemia; Nonarteritic anterior ischemic optic neuropathy

\section{INTRODUCTION}

Bilateral non-arteritic anterior ischemic optic neuropathy (NAION) is a severe condition leading to irreversible visual loss and inherent handicap. It has been rarely described for patients presenting chronic liver diseases. Different contexts are found such as hepatitis C, therapy side effects, and alcoholic liver diseases (ALD), but never anemia. However, anemia is highly prevalent in ALD patients. The optic nerve head is considered to be a territory of the central nervous system more prone to infarction during decreased blood supply. We describe the case of a patient with ALD who presented bilateral NAION as a first manifestation of severe anemia. We review reported cases of NAION in the context of chronic liver diseases. We discuss all causes, for this case and for ALD general, that contributed to anemia as well as all the mechanisms that led to isolated infarction in both optic nerve heads.

\section{Abbreviations:}

ALD, alcoholic liver disease; NAION, non-arteritic anterior ischemic optic neuropathy

\section{Corresponding author : Sébastien Richard}

Service de Neurologie, CHU Nancy, Hôpital Central, 29 Avenue du Marechal de Lattre de Tassigny-CO no 34, 54035 Nancy Cedex, France Tel: +33-3-83852256, Fax: +33-3-83851159

E-mail: s.richard@chru-nancy.fr

http://orcid.org/0000-0002-0945-5656 


\section{CASE REPORT}

The patient gave written consent for the description of the case and all data have been anonymized.

A 65-year-old woman with a medical history of high blood pressure and alcoholic cirrhosis (Child-Pugh score at B7) was admitted because of a painless and near simultaneous bilateral loss of vision (for 10 days in the right eye and 5 in the left). Slit lamp examination was normal. Fundus exams showed bilateral papilledema with hemorrhages associated with retinal venous tortuosity suggesting a diagnosis of bilateral anterior ischemic optic neuropathy (Fig. 1). Computerized perimetry showed a general reduction of the visual field around the fixation point for the right eye, and total blindness for the left.

A detailed medical interview did not find a history of headache, intermittent jaw claudication, or any other sign of giant cell arteritis. Physical examination revealed asthenia, a body mass index of 27, very pale skin and hepatomegaly. Blood pressure at admission was low at 8.8/4.6 $\mathrm{kPa}$ and the heart rate was 87 bpm.

Blood tests showed a low hemoglobin level at $48 \mathrm{~g} / \mathrm{L}$ with a normal mean corpuscular volume at $97 \mathrm{fL}$, a reticulocyte count at $40 \mathrm{G} / \mathrm{L}$, low platelet count at $91 \mathrm{G} / \mathrm{L}$ and low ferritin level at $6.9 \mu \mathrm{g} / \mathrm{L}$. C-reactive protein (3.3 mg/L), gamma glutamyl transferase, glutamic-pyruvic and glutamic-oxaloacetic transaminases, bilirubin, and thyroid-stimulating hormone levels were normal. Vitamin B1 and B6 deficiencies were noted (respectively at $38 \mathrm{nmol} / \mathrm{L}$ and $8 \mathrm{nmol} / \mathrm{L}$ ), with a normal vitamin B12 level (598 pmol/L), low level of low-density lipoprotein cholesterol $(1.3 \mathrm{mmol} / \mathrm{L})$, normal preprandial blood glucose level (4.2 $\mathrm{mmol} / \mathrm{L}$ ) and slight hyperhomocysteinemia at $32 \mu \mathrm{mol} / \mathrm{L}$. Hemostasis exploration showed high prothrombin time and activated partial thromboplastin time, low protein $\mathrm{C}, \mathrm{S}$ and antithrombin activity (respectively 32, 49 and 40\%), no activated protein $\mathrm{C}$ resistance, mutation of prothrombin gene, lupus anticoagulants or anticardiolipin antibodies. Serology was negative for human immunodeficiency virus, hepatitis B, C and Lyme disease. The main laboratory results and normal ranges are summarized in Table 1.

Brain computed tomography showed only cerebellar atrophy without any sign of infarction. Cervical and transcranial Doppler ultrasonography were normal. Liver ultrasonography and thoraco-abdomino-pelvic computed tomography showed a dysmorphic liver with peritoneal ascites without any sign of tumor. Electrocardiogram and transthoracic echocardiography did not find any cause of cardioembolism. Bone marrow aspiration showed normal presence and constitution of precursor cells. A first exploration of the digestive tract including gastroand rectosigmoidoscopy revealed chronic antral petechial gastritis which was held responsible for chronic bleeding. Helicobacter pylori was absent from antral biopsies. Further colonoscopy and gynecologic examination did not find any other cause of bleeding.

The patient underwent an initial emergency blood transfu-
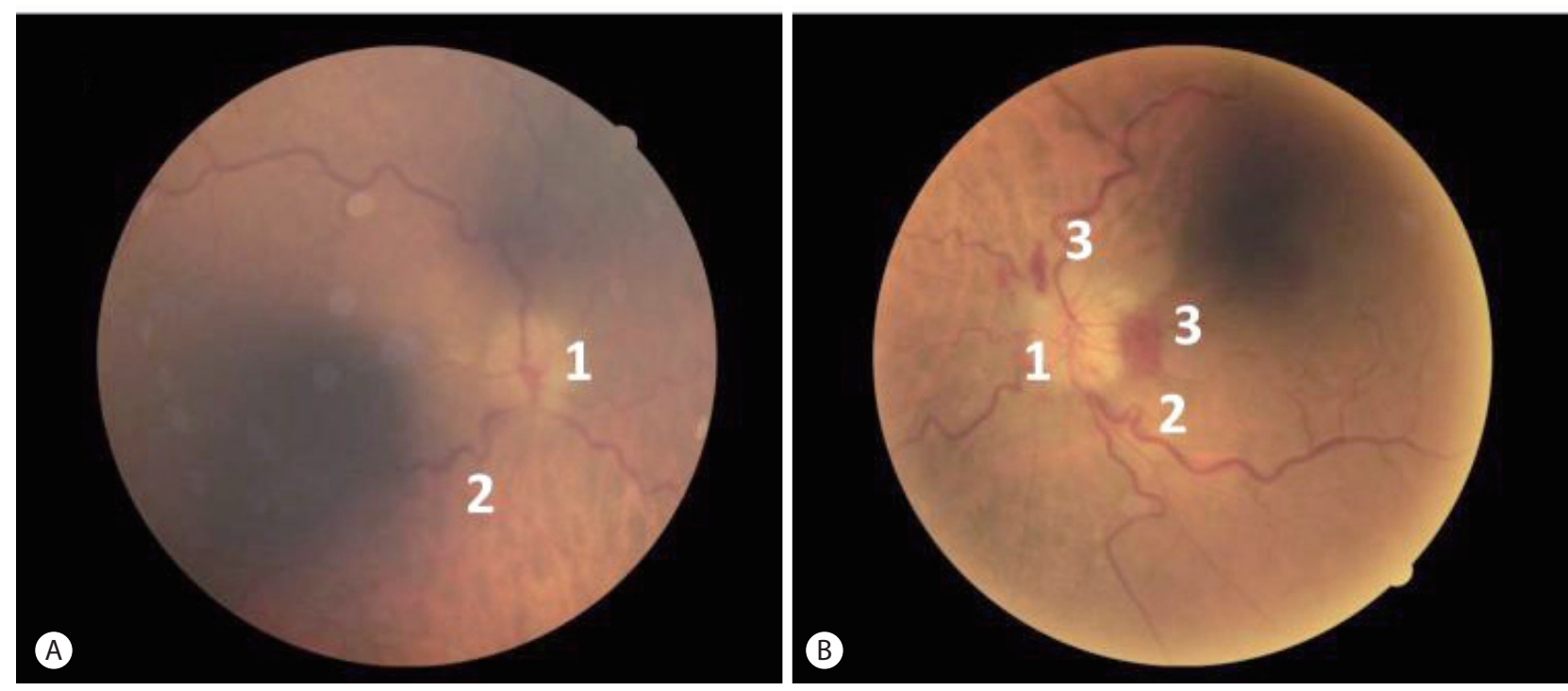

Figure 1. Fundus examinations in the acute phase of bilateral nonarteritic anterior ischemic optic neuropathy. (A) Right eye and (B) left eye. 1: papilledema, 2: retinal venous tortuosity, 3: retinal hemorrhages. 
Lisa Humbertjean-Selton, et al.

Table 1. Patient laboratory results

\begin{tabular}{|c|c|c|c|}
\hline Tests & Results & & Normal ranges \\
\hline \multicolumn{4}{|l|}{ Blood count } \\
\hline Hemoglobin & $48 \mathrm{~g} / \mathrm{L}$ & $\searrow$ & $>120 \mathrm{~g} / \mathrm{L}$ \\
\hline Mean Corpuscular Volume & $97 \mathrm{fL}$ & & $82-98 \mathrm{fL}$ \\
\hline Platelets & $91 \mathrm{G} / \mathrm{L}$ & $\searrow$ & $150-450 \mathrm{G} / \mathrm{L}$ \\
\hline Leukocytes & $4.6 \mathrm{G} / \mathrm{L}$ & & 4-10 G/L \\
\hline Neutrophils & $3.1 \mathrm{G} / \mathrm{L}$ & & $1.5-7 \mathrm{G} / \mathrm{L}$ \\
\hline Lymphocytes & $1.2 \mathrm{G} / \mathrm{L}$ & & 1-4 G/L \\
\hline Monocytes & $0.4 \mathrm{G} / \mathrm{L}$ & & $0.2-1 \mathrm{G} / \mathrm{L}$ \\
\hline Reticulocytes & $40 \mathrm{G} / \mathrm{L}$ & & $20-120 \mathrm{G} / \mathrm{L}$ \\
\hline \multicolumn{4}{|l|}{ Hemostasis } \\
\hline Prothrombin time & $20 \mathrm{~s}$ & $\nearrow$ & $<13 \mathrm{~s}$ \\
\hline Activated partial thromboplastin time & $35 s$ & $\nearrow$ & $<29 s$ \\
\hline Protein C activity & $32 \%$ & $\searrow$ & $>70 \%$ \\
\hline Protein $\mathrm{S}$ activity & $49 \%$ & $\searrow$ & $>65 \%$ \\
\hline Antithrombin activity & $40 \%$ & $\searrow$ & $80-120 \%$ \\
\hline Activated protein C resistance & Negative & & \\
\hline Mutation of prothrombin gene & Negative & & \\
\hline Lupus anticoagulants & Negative & & \\
\hline Anticardiolipin antibodies & Negative & & \\
\hline \multicolumn{4}{|l|}{ Blood biochemistry } \\
\hline Sodium & $136 \mathrm{mmol} / \mathrm{L}$ & & $136-146 \mathrm{mmol} / \mathrm{L}$ \\
\hline Potassium & $4.3 \mathrm{mmol} / \mathrm{L}$ & & $3.4-4.5 \mathrm{mmol} / \mathrm{L}$ \\
\hline Urea & $4.2 \mathrm{mmol} / \mathrm{L}$ & & $2.8-7.2 \mathrm{mmol} / \mathrm{L}$ \\
\hline Creatinine & $101 \mu \mathrm{mol} / \mathrm{L}$ & $\nearrow$ & $49-90 \mu \mathrm{mol} / \mathrm{L}$ \\
\hline \multicolumn{4}{|l|}{ Lipid and glucose profiles } \\
\hline Triglycerides & $1.1 \mathrm{mmol} / \mathrm{L}$ & & $<1.7 \mathrm{mmol} / \mathrm{L}$ \\
\hline High-density lipoprotein cholesterol & $0.8 \mathrm{mmol} / \mathrm{L}$ & & $0.8-1.8 \mathrm{mmol} / \mathrm{L}$ \\
\hline Low-density lipoprotein cholesterol & $1.3 \mathrm{mmol} / \mathrm{L}$ & . & $1.3-4.9 \mathrm{mmol} / \mathrm{L}$ \\
\hline Preprandial glucose level & $4.2 \mathrm{mmol} / \mathrm{L}$ & & $4.1-5.9 \mathrm{mmol} / \mathrm{L}$ \\
\hline \multicolumn{4}{|l|}{ Vitamins and ferritin } \\
\hline B1 & $38 \mathrm{nmol} / \mathrm{L}$ & $\searrow$ & $80-200 \mathrm{nmol} / \mathrm{L}$ \\
\hline B6 & $8 \mathrm{nmol} / \mathrm{L}$ & $\searrow$ & $20-121 \mathrm{nmol} / \mathrm{L}$ \\
\hline $\mathrm{B} 12$ & $598 \mathrm{pmol} / \mathrm{L}$ & & $96-664 \mathrm{pmol} / \mathrm{L}$ \\
\hline Homocysteine & $32 \mu \mathrm{mol} / \mathrm{L}$ & $\nearrow$ & $<15 \mu \mathrm{mol} / \mathrm{L}$ \\
\hline Ferritin & $6.9 \mu \mathrm{g} / \mathrm{L}$ & $\searrow$ & $20-200 \mu \mathrm{g} / \mathrm{L}$ \\
\hline \multicolumn{4}{|l|}{ Liver enzyme tests } \\
\hline Total bilirubin & $9 \mu \mathrm{mol} / \mathrm{L}$ & & $2-249 \mu \mathrm{mol} / \mathrm{L}$ \\
\hline Glutamate oxaloacetique transaminases & $16 \mathrm{UI} / \mathrm{L}$ & & $<35 \mathrm{UI} / \mathrm{L}$ \\
\hline Glutamate pyruvate transaminases & $25 \mathrm{UI} / \mathrm{L}$ & & $<35 \mathrm{UI} / \mathrm{L}$ \\
\hline Gamma glutamyl transferases & $30 \mathrm{UI} / \mathrm{L}$ & & $<30 \mathrm{UI} / \mathrm{L}$ \\
\hline Alkaline phosphatases & $83 \mathrm{UI} / \mathrm{L}$ & & 30-120 UI/L \\
\hline
\end{tabular}


Table 1. Continued

\begin{tabular}{|c|c|c|c|}
\hline Tests & Results & & Normal ranges \\
\hline \multicolumn{4}{|l|}{ Inflammatory markers } \\
\hline C reactive protein & $3.3 \mathrm{mg} / \mathrm{L}$ & & $<5 \mathrm{mg} / \mathrm{L}$ \\
\hline Fibrinogen & $1.2 \mathrm{~g} / \mathrm{L}$ & $\searrow$ & $1.7-4 \mathrm{~g} / \mathrm{L}$ \\
\hline \multicolumn{4}{|l|}{ Thyroid function } \\
\hline Thyroid-stimulating hormone & $1.1 \mathrm{mUl} / \mathrm{L}$ & & $0.4-3.5 \mathrm{mUl} / \mathrm{L}$ \\
\hline \multicolumn{4}{|l|}{ Serologies } \\
\hline Human immunodeficiency virus & Negative & & \\
\hline Hepatitis B & Negative & & \\
\hline Hepatitis C & Negative & & \\
\hline Lyme & Negative & & \\
\hline
\end{tabular}
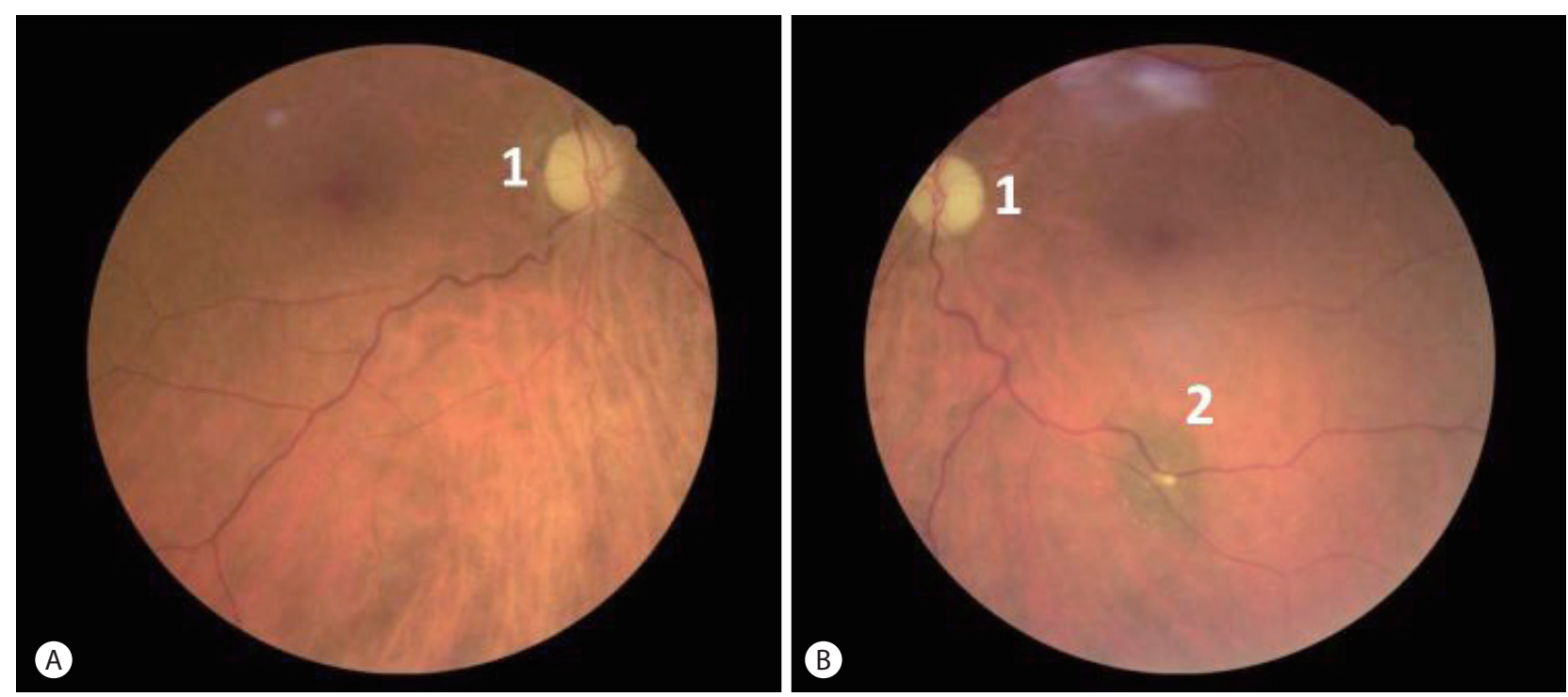

Figure 2. Control fundus examinations at 4 months after the onset of visual loss showing optic atrophy. (A) Right eye and (B) left eye. 1: papillary pallor, 2: choroidal nevus.

sion of 2 units of packed red blood cells to obtain a hemoglobin level of $77 \mathrm{~g} / \mathrm{L}$ and an arterial pressure of $11.3 / 6.2 \mathrm{kPa}$. A second transfusion was performed 2 days later. The antral gastritis was treated by a high daily dose of a proton pump inhibitor. Dietary measures with complementary vitamins (B1, B6 and B9) and iron supplements were initiated but we were unable to achieve complete alcohol consumption cessation.

After 2 years of follow up, the hemoglobin and arterial pressure levels are stable (around $80 \mathrm{~g} / \mathrm{L}$ and 11.0/7.0 kPa, respectively). The patient has not presented any other complications, but vision has not been recovered. A control fundus examination suggested poor prognosis showing atrophy of both optic nerves after resorption of papilledema (Fig. 2).

\section{DISCUSSION}

NAION during evolution of chronic liver diseases is rarely reported. Most of cases are about patients with hepatitis $C$ virus infection with two different pathways. The most frequent is related to side effects of interferon alpha therapy. Various ophthalmic complications, including ischemic neuropathy, occur in less than $1 \%$ of treated patients. Poor prognosis of NAION, bilaterality in two-thirds of cases in this context, makes authors particularly attentive to this complication.' Pathogeny is only assumed. Occlusion of optic nerve head capillaries would be due to immunologic disorders with activation of complement C5 and leucocyte aggregation, deposits of immune complexes, 
Lisa Humbertjean-Selton, et al.

and inflammation of the vessel wall caused by high cytokine levels. ${ }^{1,2} \mathrm{~A}$ role of hypotension promoted by treatment has also been suggested. Vascular risk factors (age, hypercholesterolemia and diabetes mellitus) and crowding optic disc with little cupping are considered as promoting the complication. ${ }^{2}$ Ischemic optic neuropathy as tacrolimus side effect has been described once after liver transplantation. ${ }^{3}$ Even if cases are barely reported, a direct implication of hepatitis C virus in the development of NAION is also highly suspected. ${ }^{4,5}$ Immune disorders such as vasculitis, cryoglobulins and anticardiolipin antibodies production are suggested. ${ }^{2}$ Outside the context of hepatitis $C$ and therapy side effects, only one case of bilateral NAION in a patient with ALD is found. ${ }^{6}$ This case differs from ours as the patient presented neither hypotension nor anemia. The authors assumed coagulopathy as a leading cause of bilateral ischemic optic neuropathy.

The optic nerve is divided into four anatomical segments successively called intraocular (or optic nerve head), intraorbital, intracanal, and intracranial. Anterior neuropathy is mainly due to ischemia of the optic nerve head (classically called anterior ischemic optic neuropathy). In contrast, the portion behind the eyeball is more often affected by inflammatory disease (usually referred to as retrobulbar optic neuropathy). The optic nerve is supplied by the ophthalmic artery, the first division of the internal carotid artery in the cavernous sinus, and its collaterals called retinal central, long and short posterior arteries. Vascularization of the optic nerve head is ensured by the latter. Etiologies of anterior ischemic optic neuropathy are divided into arteritic (mainly giant cell arteritis) and non-arteritic (hemodynamic, idiopathic causes, etc).

Hayreh contends that the optic nerve is a particular territory where embolism cannot be considered as a cause of ischemia and favors rather the hemodynamic theory. NAION is the result of a unique combination of different factors and causes which differs from patient to patient. Each of these factors has a distinct mechanism leading to vascular insufficiency. Classic atherosclerotic risk factors (aging, diabetes mellitus, arterial hypertension, and hypercholesterolemia) and a hyper-coagulation state can increase blood flow resistance in the optic nerve head. However, this pathway usually leads to unilateral NAION and the acquired thrombophilia due to ALD in our patient is more involved in venous thrombosis rather than arterial infarctions. Bilateral simultaneous NAION is extremely rare which suggests intervention of other mechanisms. ${ }^{7}$ Thus far, the condition has mainly been described following dialysis and surgery where patients presented hypotension and/or anemia. ${ }^{8}$ Hypotension is commonly observed in patients with alcoholic cirrhosis due to an imbalance of vasoconstrictor and dilatators agents, reduced arterial blood volume and autonomic dysfunction. ${ }^{9}$ The resulting vasoconstriction of small end arteries supplying the optic nerve head enhanced by vasoconstrictor agents leads to watershed infarctions. Visual loss is typically described on patient awakening as hypotension is deeper during sleep. ' Cerebral magnetic resonance imaging would have been of interest in our case to detect asymptomatic infarctions. However, blood flow in the brain is supported by a very efficient self-regulation system and can be maintained despite a marked decrease in arterial pressure. ${ }^{9}$ The most significant anomaly observed on our patient's admission was severe anemia as we related it to the bilateral NAION. Severe anemia reduces the oxygen-carrying ability of the blood flow. Moreover, macrocytosis and modification of erythrocyte deformability compromise the microvascular supply. ${ }^{10}$ However, it is difficult to ascertain direct causality between anemia and NAION. Indeed, as in our case, severe anemia is associated with hypotension which is a sufficient condition to promote bilateral NAION. Moreover, the patient was found to have nutritional vitamin 6 deficiency resulting in high homocysteine levels which have been associated with NAION through activation of the clotting cascade." Nevertheless, certain elements would seem to incriminate anemia. In our case, the anemia was more severe than the hypotension. Two cases of ischemic optic neuropathy, one of which was bilateral, have been described in the context of isolated anemia without hypotension., ${ }^{8,12}$ Moreover, reduced oxygen delivery to the optic nerve in the context of anemia has been shown in animal models. ${ }^{13}$

The prevalence of anemia in patients with ALD is reported as ranging from 40 to $90 \%$ depending on the diagnostic criteria. ${ }^{14,15}$ Three main mechanisms emerge from literature: bleeding and iron deficiency, a defect in bone marrow erythroblast production and hemolytic anemia. Anemia due to bleeding is nearly always encountered in the context of acute massive hemorrhage caused by disruption of esophageal varices and portal hypertension. Chronic anemia with iron deficiency due to insidious bleeding, as in our patient, is much less reported and certainly underestimated. This can be due to blood seeping out of dilated vessels due to portal hypertension. In our patient, bleeding was from antral gastritis resulting from both alcohol consumption and cirrhosis. This emphasizes the importance of attentive exploration of the gastro-intestinal tract dur- 
ing endoscopy including exploration for colon cancer. Folate deficiency, because of malnutrition with insufficient food intake and reduced jejunal absorption, is commonly described as the cause of erythroblast production defect in the bone marrow. Vitamin B6 deficiency has also been incriminated. ${ }^{16}$ Furthermore, toxicity of the alcohol itself has been highlighted in literature as directly inhibiting erythroblast synthesis and producing abnormal precursor cells leading to acquired sideroblastic anemia. ${ }^{17}$ Mechanisms of hemolytic anemia in ALD are not autoimmune. Hemolysis is the result of splenic sequestration and abnormal membrane of the erythrocytes, described as spur cells, promoting destruction. ${ }^{14,15,18}$ Hemolytic anemia can also be found in the Zieve syndrome associating jaundice, hyperlipidemia and alcoholic steatohepatitis but the pathogeny remains poorly understood. ${ }^{19}$ In addition to these three leading mechanisms, inflammation developed in ALD may contribute to anemia.

Severe anemia in our patient required urgent blood transfusion to prevent other systemic infarctions and cardiovascular complications. Description of the various causes and pathophysiological mechanisms of anemia in ALD implies etiological treatment and stopping alcohol appears to be much more important than simple iron and vitamin supplementation. ${ }^{20}$ The chronic feature of anemia in our case led to compensatory mechanisms with no, or few, clinical symptoms before such a severe and irreversible complication as blindness. This emphasizes the importance of detecting anemia in ALD patients.

In conclusion, anemia is a frequent, multi-etiological complication of ALD which can be difficult to detect due to a long and progressive onset. This can result in dramatic complications such as bilateral NAION which is the result of reduced oxygen delivery and vascular insufficiency due to inherent hypotension. Hemoglobin levels should therefore be routinely monitored as part of ALD patient management. Mechanisms of anemia are directly linked to alcohol toxicity and hepatopathy which reinforces the importance of stopping alcohol consumption as part of the therapeutic strategy.

\section{Authors' contribution}

LHS, SR, and JS designed the work, collected data and drafted case presentation and figures. LHS, SR, JS, NRC, JCL and GM conducted the literature review and drafted the introduction and discussion sections. All authors revised the manuscript critically for important intellectual content and have given their approval of the final submitted version.

\section{Acknowledgments}

Felicity Neilson, Matrix Consultants, for having reviewed the English language with scientific expertise.

\section{Conflicts of Interest}

The authors have no conflicts to disclose.

\section{REFERENCES}

1. Fraunfelder FW, Fraunfelder FT. Interferon alfa-associated anterior ischemic optic neuropathy. Ophthalmology 2011;118:408-411.

2. Berg KT, Nelson B, Harrison AR, McLoon LK, Lee MS. Pegylated interferon alpha-associated optic neuropathy. J Neuroophthalmol 2010;30:117-122.

3. Brazis PW, Spivey JR, Bolling JP, Steers JL. A case of bilateral optic neuropathy in a patient on tacrolimus (FK506) therapy after liver transplantation. Am J Ophthalmol 2000;129:536-538.

4. Prud'homme S, Nevens F, Casteels I. Bilateral simultaneous anterior ischemic optic neuropathy, an extrahepatic manifestation of hepatitis C cured with direct acting antivirals. GMS Ophthalmol Cases 2016;6:Doc05.

5. Sinnreich M, Rosillion B, Landis T, Burkhard PR, Sztajzel R. Bilateral optic ischemic neuropathy related to chronic hepatitis $C$-associated anticardiolipin antibodies. Eur Neurol 2003;49:243-245.

6. Bassi ST, Dasqupta A. Bilateral simultaneous nonarteritic anterior ischemic optic neuropathy in a patient with alcoholic liver disease. Oman J Ophthalmol 2014;7:72-74.

7. Hayreh SS. Ischemic optic neuropathy. Prog Retin Eye Res 2009;28: 34-62.

8. Haider S, Astbury NJ, Hamilton DV. Optic neuropathy in uraemic patients on dialysis. Eye (Lond) 1993;7:148-151.

9. Møller S, Henriksen JH. Cardiovascular complications of cirrhosis. Gut 2008:57:268-278.

10. McMurran AE, Adair RA. Macrocytosis and sudden sensorineura hearing loss: a case report. J Laryngol Otol 2015;129:1137-1139.

11. Kawasaki A, Purvin V, Burgett RA. Hyperhomocysteinaemia in young patients with non arteritic anterior ischaemic optic neuropathy. Br J Ophthlmol 1999;83:1287-1290.

12. Golnik KC, Newman SA. Anterior ischemic optic neuropathy associated with macrocytic anemia. J Clin Neuroophthalmol 1990;10:244-247.

13. Lee LA, Deem S, Glenny RW, Townsend I, Moulding J, An D, et al. Effects of anemia and hypotension on porcine optic nerve blood flow and oxygen delivery. Anesthesiology 2008;108:864-872.

14. Bladé JS, Desramé J, Corberand D, Lecoules S, Blondon H, Carmo $\mathrm{T}$, et al. Diagnosis of anemia in alcoholic cirrhosis. Rev Med Interne 2007;28:756-765.

15. Mathurin SA, Agüero AP, Dascani NA, Prestera JA, Gianserra C, 
Lisa Humbertjean-Selton, et al.

Blindness related to anemia in alcoholic cirrhosis

Londero $\mathrm{E}$, et al. Anemia in hospitalized patients with cirrhosis: prevalence, clinical relevance and predictive factors. Acta Gastroenterol Latinoam 2009;39:103-111.

16. Gonzalez-Casas R, Jones EA, Moreno-Otero R. Spectrum of anemia associated with chronic liver disease. World J Gastroenterol 2009;15:4653-4658.

17. Tenner S, Rollhauser C, Butt F, Gonzalez P. Sideroblastic anemia. A diagnosis to consider in alcoholic patients. Postgrad Med
1992;92:147-150.

18. Murphy CH, Jain S, Sabath DE, Chatta GS, Hess JR. Spur cell hemoIytic anemia in liver failure. Transfusion 2016;56:787-788.

19. Melrose WD, Bell PA, Jupe DM, Baikie MJ. Alcohol-associated haemolysis in Zieve's syndrome: a clinical and laboratory study of five cases. Clin Lab Haematol 1990;12:159-167.

20. Shah VH. Managing alcoholic liver disease. Clin Mol Hepatol 2015;21:212-219. 